\title{
Projeto Colmeia: Gamificando no Ensino Superior
}

\author{
Paulo André da Silva
}

\author{
Universidade Federal de Pernambuco (UFPE) \\ Centro Acadêmico de Vitória (CAV)
}

[profe.pas@gmail.com / paulo.silva@ufpe.br]

\begin{abstract}
This article describes a gamification process in pedagogical disciplines for an undergraduate course. The "Colmeia" project aims to integrate motivational actions with content of the disciplines of 'Didactics' and 'Assessment of Learning', within a narrative inspired by bee's lives. The objective is to involve students in motivational activities related to real data, content, skills development and practical actions in schools. We use a variety of digital tools to promote creative problem-solving actions to accomplish the main mission of the game.
\end{abstract}

Resumo. Este artigo descreve um processo de gamificação em disciplinas pedagógicas para curso de licenciatura. O projeto Colmeia visa integrar ações motivacionais com conteúdos próprios das disciplinas de 'Didática' $e$ 'Avaliação da Aprendizagem', dentro de uma narrativa inspirada na vida das abelhas. Objetiva envolver estudantes em atividades motivacionais, relacionadas com dados da realidade, conteúdos, desenvolvimento de competências e habilidades e ações práticas em escolas. Utilizamos diversas ferramentas digitais para promoção de ações criativas na resolução de problemas, de forma a conduzir ao cumprimento da missão principal do jogo.

\section{Introdução}

Considerando as novas demandas de formação para o atual sistema de produção e de relações humanas, sob um universo de impactos das tecnologias digitais e de sistemas de comunicação avançados, pensamos que a formação inicial de futuros professores deve corresponder a esse novo contexto [Junges \& Behrens, 2016; Morin, 2002]. Ainda considerando o Ensino Superior como locus para construção de conhecimentos, compreendemos a necessidade de implementar processos que estimulem o desenvolvimento ou aprimoramento de competências e habilidades que dêem conta das necessidades atuais no campo da educação (e outros).

Propomos esse projeto de gamificação com o objetivo de engajar e motivar os estudantes para criação de experiências de aprendizagem [Gomes \& Silva, 2016] relacionadas a conteúdos próprios das disciplinas de Didática e Avaliação da Aprendizagem, em curso de Licenciatura em uma IES Federal. Este engajamento se deu a partir da adesão aos desafios propostos que orientaram os estudantes à aprendizagens experienciais de conteúdos, habilidades e competências que resultaram na construção de 
jogos didáticos e de processos avaliativos formativos, sendo estes os elementos finais da missão do jogo.

Para fins de fundamentar nossas ações, estabelecemos as relações conceituais entre Gamificação, Avaliação Formativa e Processos Didáticos com base em metodologias ativas. Desta forma, podemos relatar neste artigo a complexidade de planejamento destas ações e decisões tomadas para que houvesse sucesso na construção do Colmeia Game.

\section{Processo de Gamificação}

Tomamos como definição de gamificação o conceito de Alves et al (2014, p.76), a qual indica que a gamificação "[...] se constitui na utilização da mecânica dos games em cenários non games, criando espaços de aprendizagem mediados pelo desafio, pelo prazer e entretenimento". Este cenário non game é o mundo real, no nosso caso a Universidade, necessitando assim vincular conteúdos necessários para a formação dos estudantes, agregando elementos motivadores para aprendizagem ativa dos mesmos.

Como se propõe na construção de um bom jogo, este deve estar associado a uma narrativa que gere envolvimento dos jogadores e que seja interessante [Kaap, 2012]. Criamos então a narrativa ligada a vida das abelhas, partindo da ideia que uma instituição de ensino deve funcionar como uma colônia de abelhas, na qual há trabalhos individuais e coletivos, com funções diferentes entre os atores escolares (abelhas), mas todos voltados para o desenvolvimento e ampliação da instituição (colmeia), ou seja, para o bem coletivo e próspero daquele espaço.

Tomamos essa narrativa considerando que são estudantes em formação para a docência na área de biologia e, como tal, precisam criar uma identidade relacionada à área de conhecimento específica, assim como ao espaço escolar, vivenciando não apenas conteúdos que falam sobre este espaço, mas produzindo e executando ações no espaço escolar, ampliando as perspectivas da própria formação. Para isto, vinculamos o Colmeia Game a um projeto de extensão que possibilitasse essa comunicação com o espaço escolar.

No Colmeia Game os estudantes são desafiados a construírem um caminho que envolve ações individuais e coletivas/colaborativas, cuja meta é planejar, construir e avaliar jogos didáticos que abordem conteúdos da biologia, em especial da área de Zoologia. Os jogos didáticos são produtos finais do trabalho dos estudantes e representa o mel da colmeia. Neste processo ainda devem envolver estudantes e professores de escolas públicas, de forma que dê sentido a saída das abelhas da colmeia para expansão e construção de uma 'nova colônia', uma vez que aquela colmeia já esteja em plena produção.

O Colmeia Game possui uma missão única e cinco fases que, ao serem desenvolvidas, fornecem aos estudantes elementos necessários para a realização dessa missão, a saber: encontrar alternativas para promover ideias e possíveis ações para estimular, entre os atores de escolas públicas, a inserção de processos criativos na construção e avaliação de jogos didáticos para a aprendizagem de conteúdos de ciências/biologia. 
As fases do Colmeia Game compreendem as camadas de uma colmeia de abelhas. Apesar de algumas variações na sua arquitetura, dependendo da espécie, há uma ordenação mais comum entre várias espécies, a qual nos inspirou para determinar as fases do jogo. Na parte mais alta da colmeia é guardado o mel, em seguida o pólen, depois as larvas e ovos mais ao centro, uma área onde ficam os zangões e o alvéolo real, na qual a abelha rainha se instala até colocar todos os ovos para depois sair em busca de novo local para criar uma nova colônia, juntamente com outras abelhas operárias.

Fizemos uma analogia às fases do design de planejamento, enquanto processo criativo, no qual precisa (i) entender e conhecer o problema, fase muito preciosa para que seja possível chegar à resolução de um problema, consideramos aqui o principal "produto" de um planejamento (depósito de mel). (ii) Levantamento de recursos, de ideias criativas com potencial para criação do mel (depósito de pólen). (iii) Fase de prototipagem, criação de um modelo potencial do jogo didático para manutenção concreta da colmeia (depósito de larvas e ovos). (iv) Aplicação do modelo, momento de testagem do protótipo com fins de replicar o modelo planejado, mas agora em contexto real. (área dos zangões), uma vez que estes têm a única função de replicar a colônia, o modelo aqui ocupa função similar, desde que devidamente avaliado em sua execução. (v) Fase da avaliação final, retroalimentando o processo a partir de uma avaliação mais ampliada (alvéolo real), traçando um paralelo com a função da abelha rainha, a qual tem a função principal de manutenção e ampliação das colônias, a avaliação também ocupa um papel fundamental no processo pedagógico.

Cada fase de jogo foi composta por 8 desafios coletivos (Bee Colônia) e 4 desafios individuais (Bee), todos relacionados a conteúdos específicos das disciplinas e/ou a competências que precisavam ser desenvolvidas entre os estudantes. Os desafios foram liberados de acordo com a conclusão do anterior e respectivas avaliações, de forma que o mediador (professor) pudesse ponderar qual melhor caminho a seguir. Houve pouca variação temporal entre as equipes, já que todas estavam terminando os desafios praticamente no mesmo tempo.

Cada desafio teve uma pontuação específica, chamada de "meles" no contexto do jogo, compondo um ranking das equipes. Os meles foram transformados em nota para a disciplina ao final do processo. Houve desafios para equipes, chamados de 'desafios colônia' e também desafios individuais, chamados de 'desafios bee'.

O Colmeia Game teve um caráter colaborativo e não competitivo, pois os desafios demandaram cooperação e colaboração não só entre os integrantes das mesmas equipes, mas também entre as equipes. Desta forma trazemos ao contexto das práticas o desenvolvimento de cinco competências que entendemos serem importantes para qualquer pessoa, em qualquer campo de atuação social e profissional. Denominamos estas competências em BeeGroup, estimulada pelas ações de trabalho em equipe; BeeTime, focalizando aspectos de gestão de tempo e responsabilidade; BeeTalk focada em questões comunicacionais; BeePlan com desafios que estimulam processos criativos de planejamento de ações e a competência BeeLove (empatia) que remonta elementos de colaboração e cooperação e pode ser vivenciada e avaliada sob critérios mais palpáveis e não apenas fazer parte de um discurso ou de uma visão meramente subjetiva. 


\section{Contexto teórico para formação do Colmeia}

Vivenciamos hoje a $4^{\text {a }}$ revolução industrial [Schwab, 2017], a qual impõe novos modelos de produção e de relações sociais que criam uma disruptura com formas que tradicionalmente eram usadas para interações sociais e profissionais. Partindo da premissa que já vivemos uma era imersa na complexidade [Morin, 1994], chamando aqui de 'era complexa', esta impõe desafios novos em termos de construção de uma sociedade interconectada, cujas relações com os sistemas de automação tecnológica e inteligência artificial (IA) nos colocam frente a escolhas que não mais requerem reproduções de informações, mas sim ações reflexivas e reativas próprias dos humanos [Roberts, 2015]. Dentre estas podemos considerar a habilidade de se relacionar, de demonstrar afeto, empatia, se divertir, entre outras ações que têm nas relações o seu cerne. Assim, requisita-se focar os modelos de ensino de forma que favoreçam a aprendizagem, a construção de conhecimentos mais focada em desenvolvimento de habilidades e competências, em pessoas, para que os estudantes consigam resolver problemas de forma criativa e crítica.

No contexto da Licenciatura, sem deixar de lado a função social do ensino em estimular ações vinculadas à vida pessoal, social e profissional que os estudantes ocupam e ocuparão, colocamos como objeto de estudo um processo dialógico e pretensamente divertido no modelo de trabalho das disciplinas de Didática e Avaliação da Aprendizagem, articulando com ações fora do campus universitário: em escolas públicas de região do interior de Pernambuco.

Assim, inspirados por autores como Alves et al. (2014); Huizinga (1993); Kapp (2012); Morin (2002); Schlemmer (2014) e Ulbricht e Fadel (2014), entendemos que a inserção de jogos, de processos lúdicos ou de gamificação possam favorecer o engajamento e a aprendizagem dos estudantes, além de favorecer a busca pela atuação nas escolas de educação básica, ampliando a comunicação e relação Universidadesociedade, no caso as escolas [Freire, 2000; 2006], levando os estudantes do curso a intervirem positivamente e colaborativamente nas práticas de ensino com proposições de jogos didáticos para o ensino das ciências/biologia.

Verificamos que a narrativa do jogo e as etapas que o mesmo dispôs levaram os estudantes a planejarem, criarem, compartilharem e intervirem positivamente nas escolas de educação básica, de forma que foi possível construir conhecimentos específicos dos conteúdos das disciplinas envolvidas, assim como desenvolverem competências necessárias para formação acadêmica e futura atuação como docentes do século XXI.

\section{Objetivos}

Temos como objetivo deste artigo descrever o processo de gamificação para promoção de competências e habilidades para docência durante a formação inicial na graduação.

Mais especificamente em relação aos objetivos do processo de gamificação, elencamos:

1. Engajar os estudantes através de ações diversificadas motivando-os a um trabalho divertido e essencialmente comunicacional.

2. Estimular a reflexão teoria/prática na interação com o espaço escolar. 
3. Promover outras formas de ensinar e aprender, diferentes do modelo tradicional (transmissor-receptor) de ensino.

4. Enfatizar processos de aprendizagem e desenvolvimento de competências e habilidades.

5. Estimular o trabalho interdisciplinar e colaborativo entre estudantes e professores na Licenciatura.

6. Criar instrumentos e critérios avaliativos que demarquem um processo de avaliação formativa.

\section{Metodologia}

Resumiremos aqui as etapas do processo de implantação da gamificação no Ensino Superior, de forma a atender nosso objetivo deste artigo, mas apontando alguns elementos que consideramos relevante descrever para melhor compreensão do que fizemos neste Projeto.

Essencialmente partimos do emprego de metodologias ativas para instalar um processo criativo entre os estudantes, com fins na construção e aplicação de jogos didáticos. Envolvendo as seguintes etapas:

1. Planejamento do Colmeia Game - elaboração de desafios, com base nos conteúdos das disciplinas, que façam um sentido lógico de construção do conhecimento, gerenciando este processo através de uma plataforma online. A princípio foi usada a sala de aula virtual da Google - Google Classroom. Neste espaço foram lançados desafios em formas de "atividades" e, pela ferramenta online, podemos dar feedbacks individual e coletivo, uma vez que as equipes se inscreveram como sendo um aluno desta sala (criaram um perfil da equipe).

2. Conceituação do processo de gamificação - envolveu a proposição de desafios aos estudantes da graduação, dentro de uma narrativa ligada a vida das abelhas. Tais desafios foram relacionados aos conteúdos necessários para a construção de jogos didáticos, estabelecendo um elo conceitual entre a prática de ensino e as ações que foram executadas nas escolas. Desta forma os estudantes puderam se munir de instrumentos necessários para a consecução da missão do Colmeia Game, partindo do pressuposto que as escolas envolvidas demonstram, em sondagem prévia, poucas práticas interativas e principalmente lúdicas.

3. Motivação e engajamento dos estudantes - Tendo em vista promover o interesse e engajamento dos estudantes, propomos um roteiro gamificado das disciplinas de Didática e Avaliação da Aprendizagem, nas quais os estudantes foram instrumentalizados conceitualmente e praticamente para a resolução de problemas focados na missão do jogo.

4. Prototipação - Foram construídos 06 jogos didáticos em sintonia com processos de organização curricular das escolas, alinhando os conceitos com os respectivos professores das escolas, de forma que a intervenção não se tornasse um evento a parte na escola, mas sim algo que nutrisse as próprias relações educacionais. Favorecendo uma comunicação positiva entre a Universidade e as escolas e não apenas um mero uso do espaço escolar para uma prática isolada. 
5. Construção conceitual dos jogos - Os jogos didáticos produzidos pelos estudantes abordaram conteúdos da Zoologia, fazendo alusão curricular com o objeto conceitual mais amplo do curso de Licenciatura em Ciências Biológicas, além de justificar uma parceria em um evento com professores desta disciplina. Podemos considerar aqui uma pequena ampliação da interdisciplinaridade que visualizamos para esse projeto.

6. Gestão de processos - Foi implantado um processo de gestão criativo, com uso de recursos tecnológicos, favorecendo a comunicação entre os próprios estudantes e destes com o professor, assim como com os estudantes monitores do projeto. Os estudantes apresentaram seus progressos na sala de aula Google (Google Classroom) e no aplicativo Trello (gestão de atividades). Sendo este último também utilizado para gestão do processo de concepção dos desafios do Colmeia, juntamente com a equipe de monitores das disciplinas.

7. Manutenção motivacional - Implantamos elementos físicos motivadores, os quais foram relacionados às habilidades e competências que este Projeto visou estimular. Os estudantes receberam bótons (figura 1) ao se destacarem nas áreas de: planejamento (BEEPLAN); gestão de tempo (BEETIME); empatia (BEELOVE); comunicação (BEETALK) e trabalho em equipe (BEEGROUP). Além dos botons, recebiam "meles" que correspondia a uma pontuação específica para cada tipo de desafio. Estes meles se converteram em notas ao final do processo.
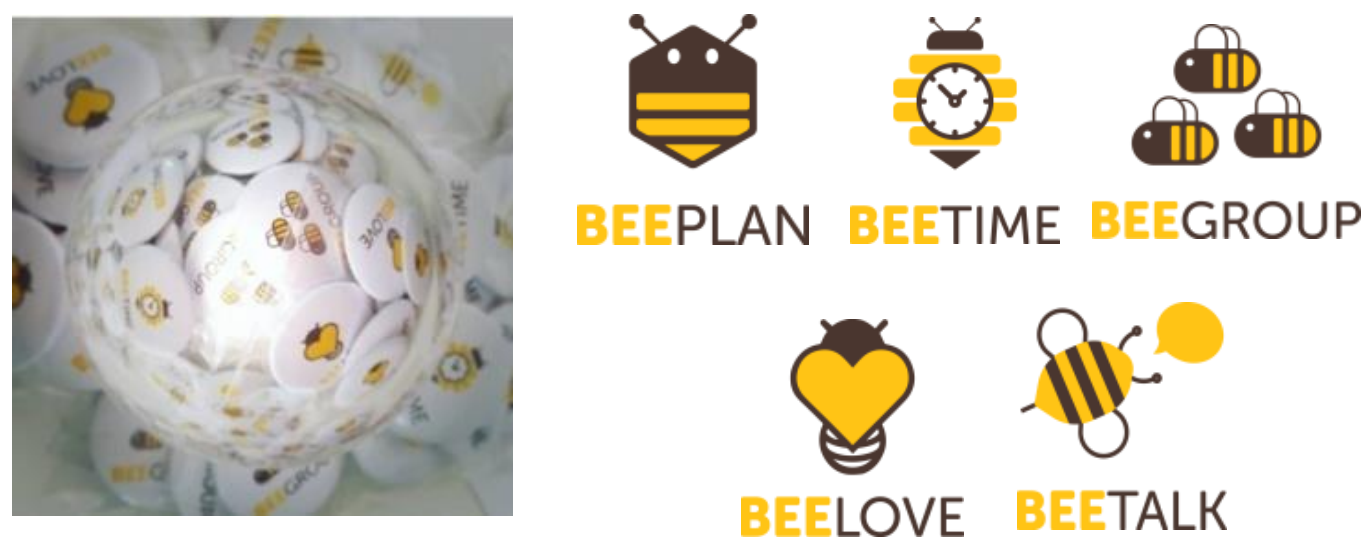

Figura 1. Elementos de estímulo no jogo (bótons)

8. Aplicação nas escolas - As equipes de estudantes, devidamente preparadas, realizaram suas intervenções em parceria com os professores das escolas, 
promovendo seus jogos didáticos e gerando relações que motivassem os estudantes das escolas a construírem relações conceituais com os jogos aplicados e conteúdos que estavam estudando ou que iram estudar (em 2 casos), assim como a possibilidade de construção de novos jogos.

9. Comunicação - Além dos pontos de interação prévia com as escolas, os estudantes colaboradores deveriam envolver o máximo possível de atores escolares na dinâmica dos seus jogos, de forma a gerar um clima de aprendizagem para outros eventuais sujeitos que quisessem participar dos momentos de intervenção. Além disso, apresentaram suas experiências com os jogos didáticos em evento próprio do curso. Outro aspecto comunicacional foi ligado à forma de registros fotográficos e videográficos realizados nas escolas, de forma que comunicassem uma narrativa do que foi realizado, isto para fins de prestação de relatório final, comunicando visualmente e textualmente suas experiências.

10. Avaliação - Foram criados formulários com critérios que abrangiam a compreensão da construção dos jogos didáticos pelos estudantes da graduação, assim como sua aplicação nas escolas básicas. Os instrumentos e critérios avaliativos foram propostos e construídos pelos estudantes da disciplina de Avaliação da Aprendizagem, compondo seus desafios neste caminho de processo avaliativo formativo. Desta forma foi possível avaliar continuamente o Colmeia Game, verificando a efetividade do projeto em termos de engajamento de estudantes, na apropriação de conteúdos, aplicação dos jogos didáticos nas escolas, aspectos motivacionais para construção de modelos destes jogos, aspectos relacionados ao desenvolvimento das competências citadas no item 6 acima. Essas ações avaliativas contribuíram para criação de um clima positivo em relação aos processos de aprendizagem, valorizando a formação dos estudantes e não apenas os resultados finais das atividades (desafios) realizadas.

\section{Considerações Finais}

Por meio desta experiência pedagógica, podemos considerar, pelos depoimentos dos estudantes de ambas disciplinas, quando questionados sobre o que acharam do processo de gamificação, que se constituiu um diferencial nos processos de ensino e aprendizagem, adequando-se ao contexto da cultura digital, uma vez que estimulamos e usamos ferramentas digitais diversas, aplicadas dentro de um contexto relacional, dando sentido ao uso em si.

"Não gostava de cadeiras de educação por sempre achá-las chatas.
Mas quando o professor transformou a cadeira em um jogo, ficou bem
mais divertido participar. Foi uma verdadeira experiência de
'aprender brincando'. Tornou a cadeira minha melhor experiência
nas cadeiras de educação. Gostei de ter participado e de estar dentro
do 'jogo'. Me senti importante, como uma operária dentro da colmeia
kkkkkkk" (depoimento de aluno da disciplina de Avaliação da
Aprendizagem).

Além disso, percebemos que este tipo de iniciativa didática também contribuiu positivamente para formação dos estudantes, dando-lhes experiência prático-conceitual, em especial no desenvolvimento de competências necessárias neste cenário sociocultural do século XXI. 
"Achei muito criativa, e eu futuramente pretendo colocar em prática com meus futuros alunos". (depoimento de aluna da disciplina de Didática)

Por ainda ter um caráter experimental, o Colmeia Game está sujeito a testes e taxas razoáveis de falhas, como percebemos algumas ao longo do tempo, o que nos possibilitou abrir espaço necessário de investigação e necessários ajustes. Mas ao mesmo tempo, possibilitou expandir potencialmente entendimentos e explorações sobre novas práticas pedagógicas que sejam bem planejadas e acreditamos bem-sucedidas.

As dificuldades até aqui encontradas refere-se a uma plataforma mais adequada para promover uma imersão dos estudantes no ambiente do jogo. Após consulta aos estudantes, percebemos a necessidade de construção de um site específico para o Colmeia e estamos trabalhando na construção deste material a fim de promover maior engajamento dos estudantes no contexto narrativo do jogo.

O processo de gamificação no ensino superior não é simples de ser implantado, levando em consideração a complexidade de planejamento que deve ser feito e a diminuta equipe de concepção e execução do jogo, a qual, a princípio, é realizada mais fortemente pelo próprio professor das disciplinas com suporte de monitores na parte executiva. Mas este elemento não é desanimador, mas sim desafiador, uma vez que a gamificação se tornou, em nossa experiência, forte aliado no processo de promoção de novas práticas educacionais e favorecedora de engajamento dos estudantes na construção do conhecimento. Percebemos que ainda há necessidade de investimentos e mais pesquisas sobre sua efetividade em termos de aprendizagem e outras perspectivas que aludem o ambiente educacional universitário.

\section{Referências}

Alves, L.R. et al. (2014). Gamificação: diálogos com a educação. In: Fadel, Luciane Maria et al (Org.). Gamificação na educação. São Paulo: Pimenta Cultural [e-book]

Freire, P. (2000). Pedagogia da Indignação: cartas pedagógicas e outros escritos. São Paulo: Editora UNESP.

Freire, P. (2006) Extensão ou Comunicação. 13ª edição. São Paulo: Paz e Terra.

Gomes, A.S. \& Silva, P.A. (2016). Design de Experiências de Aprendizagem: Criatividade e inovação para o planejamento de aulas. Série Professor Criativo. Recife: Pipa Comunicação, 162p.

Huizinga, J. (1993) Homo Ludens: o jogo como elemento da cultura. $4^{\text {a }}$ edição. São Paulo: Editora Perspectiva.

Junges, K.S. \& Behrens, M.A. (2016). Uma formação pedagógica inovadora como caminho para a construção de saberes docentes no Ensino Superior. Educar em Revista, (59), 211-229. https://dx.doi.org/10.1590/0104-4060.42282

Kapp, K. (2012). The Gamification of Learning and Instruction: Game-based Methods and Strategies for Training and Education. San Francisco: Pfeiffer.

Morin, E. (2002). Os sete saberes necessários à educação do futuro. $5^{\mathrm{a}}$ edição. São Paulo: Cortez; Brasília: UNESCO.

Schwab, K. (2016). A quarta revolução industrial. Tradução: Daniel Moreira Miranda. São Paulo: Edipro. Título original: The Fourth Industrial Revolution. 
Schlemmer, E. (2014). Gamificação em espaços de convivência híbridos e multimodais: design e cognição em discussão. Revista da FAEEBA - Educação e Contemporaneidade, Salvador, v. 23, n. 42, p. 73-89, jul/dez.

Ulbricht, V.R.; Fadel, L.M. (2014). Educação gamificada: valorizando os aspectos sociais. In: Fadel, Luciane Maria et al (Org.). Gamificação na educação. São Paulo: Pimenta Cultural [e-book]. 